\title{
Beam-Target Interaction Experiments for Bremsstrahlung Converter Applications
}

S. Sampayan, G. Caporaso, Y-J. Chen, S. Falabella, D. Ho, T. Houck, E. Lauer, J. McCarrick, R. Richardson, D. Sanders, and J. Weir

This article was submitted to $20^{\text {th }}$ International Linear Accelerator Conference Monterey, $C A$

U.S. Department of Energy

August 21-25, 2000

Lawrence

Livermore

National

Laboratory

August 1, 2000 


\section{DISCLAIMER}

This document was prepared as an account of work sponsored by an agency of the United States Government. Neither the United States Government nor the University of California nor any of their employees, makes any warranty, express or implied, or assumes any legal liability or responsibility for the accuracy, completeness, or usefulness of any information, apparatus, product, or process disclosed, or represents that its use would not infringe privately owned rights. Reference herein to any specific commercial product, process, or service by trade name, trademark, manufacturer, or otherwise, does not necessarily constitute or imply its endorsement, recommendation, or favoring by the United States Government or the University of California. The views and opinions of authors expressed herein do not necessarily state or reflect those of the United States Government or the University of California, and shall not be used for advertising or product endorsement purposes.

This is a preprint of a paper intended for publication in a journal or proceedings. Since changes may be made before publication, this preprint is made available with the understanding that it will not be cited or reproduced without the permission of the author.

This report has been reproduced directly from the best available copy.

Available electronically at http://www.doc.gov/bridge

Available for a processing fee to U.S. Department of Energy

And its contractors in paper from

U.S. Department of Energy

Office of Scientific and Technical Information

P.O. Box 62

Oak Ridge, TN 37831-0062

Telephone: (865) 576-8401

Facsimile: (865) 576-5728

E-mail: reports@adonis.osti.gov

Available for the sale to the public from

U.S. Department of Commerce

National Technical Information Service

5285 Port Royal Road

Springfield, VA 22161

Telephone: (800) 553-6847

Facsimile: (703) 605-6900

E-mail: orders@ntis.fedworld.gov

Online ordering: http:/ / www.ntis.gov/ordering.htm

\section{OR}

Lawrence Livermore National Laboratory

Technical Information Department's Digital Library

http: / / www.llnl.gov/tid/Library.html 


\title{
BEAM-TARGET INTERACTION EXPERIMENTS FOR BREMSSTRAHLUNG CONVERTER APPLICATIONS ${ }^{*}$
}

\author{
S. Sampayan, G. Caporaso, Y-J Chen, S. Falabella, , D. Ho, T. Houck, \\ E. Lauer, J. McCarrick, R. Richardson, D. Sanders, and J. Weir \\ Lawrence Livermore National Laboratory, Livermore, California 94550 USA
}

\begin{abstract}
The DARHT II accelerator uses a pulsed high current electron beam and Bremsstrahlung converter target to generate an intense $x$-ray source for radiography. For the past several years, we have been performing an investigation of the possible adverse effects of (1) backstreaming ion emission from the Bremsstrahlung converter target and (2) the interaction of the resultant plasma with the electron beam during subsequent pulses. These effects would manifest themselves in a static focusing system as a rapidly varying $x$-ray spot. To study these effects, we are conducting beam-target interaction experiments on the ETA-II accelerator (a $6.0 \mathrm{MeV}, 2.5 \mathrm{kA}$, 70 ns FWHM pulsed induction LINAC). We have determined spot dynamics and characterized the resultant plasma for various configurations. Our experiments show that the first effect is not strongly present when the beam initially interacts with the target. Electron beam pulses delivered to the target after formation of a plasma are strongly affected, however. We have also performed initial experiments to determine the effect of the beam propagating through the plasma. This data shows that the head of the beam is relatively robust, but that backstreaming ions from the plasma can induce a dynamic focus toward the tail of the beam. We survey the results of our experiments and attempts to suppress the adverse effects we have observed.
\end{abstract}

\section{INTRODUCTION}

The DARHT II system is a multi-pulse, single-axis flash radiography system being built at Los Alamos National Laboratory. This system is designed to be capable of taking closely spaced radiographic images so as to produce time-sequenced images of the test object.

The DARHT II accelerator is nominally a $20 \mathrm{MeV}, 2 \mathrm{kA}$, $2 \mu$ single pulse accelerator. Four pulses at the target over a $2 \mu \mathrm{s}$ window are derived from this single pulse with a fast kicker system. The electron beam interacting with the converter target (typically tantalum) generates an intense $x$-ray cone that produces a radiographic image on a fast detector array.

As the electron beam interacts with the target surface, a plasma promptly develops. The beam electrons create a strong space charge field in front of the target from which ions can be extracted and accelerated in a direction opposite to the electron beam propagation. These ions partially neutralize the beam space charge and defocusing of the beam results.

The second effect results from the direct interaction of the electron beam with the target plasma on subsequent pulses. Such an interaction, depending on the interaction length and plasma density, may have an adverse effect on the beam propagation and the resultant spot on the converter target.

Our on-going experimental program is to study the interaction of the electron beam with the x-ray converter target. In these experiments, we focus on the dynamics of the spot behavior measuring xray spot biur across an edge (so called "roll-bar" technique), and 2-d imaging with a gated, multiframe, pinhole camera. Further, we are characterizing the properties of the plume by using various plasma diagnostic techniques.

\section{EXPERIMENTAL}

We described our experimental set-up and preliminary experiments in a previous paper [1]. Figure 1 shows a representative sample of images from the xray pinhole camera. Gate time of each image is approximately $6 \mathrm{~ns}$ and spacing between images is $7-10 \mathrm{~ns}$. Time position relative to the beam current pulse is shown in the lower portion of the figure.

Images taken with the beam at normal incidence show an almost constant spot diameter. An intensity profile through the center of each image shows a $1 \mathrm{~mm}$ spot diameter (FWHM) for this beam current of $1.4 \mathrm{kA}$. We observe similar results from this current up to the maximum ETA-II operational current of approximately 2.0 $\mathrm{kA}$. These data show an almost constant spot radius with a variation of approximately $25 \%$. Additionally, in this data, we do not observe evidence of backstreaming ions with the Faraday cups (figure 2). In this figure are shown our expectation for observing various species of fast backstreaming ions from the target.

As most models predict that the backstreaming ion effect can manifest itself in the focus more promptly for lighter species, we conducted multiple experiments with light element surface layers (down to mass 2) or with 
lighter element target substrates (down to mass 12). In all these experiments, we were unable to observe a dynamically varying spot diameter or any evidence of backstreaming ions.
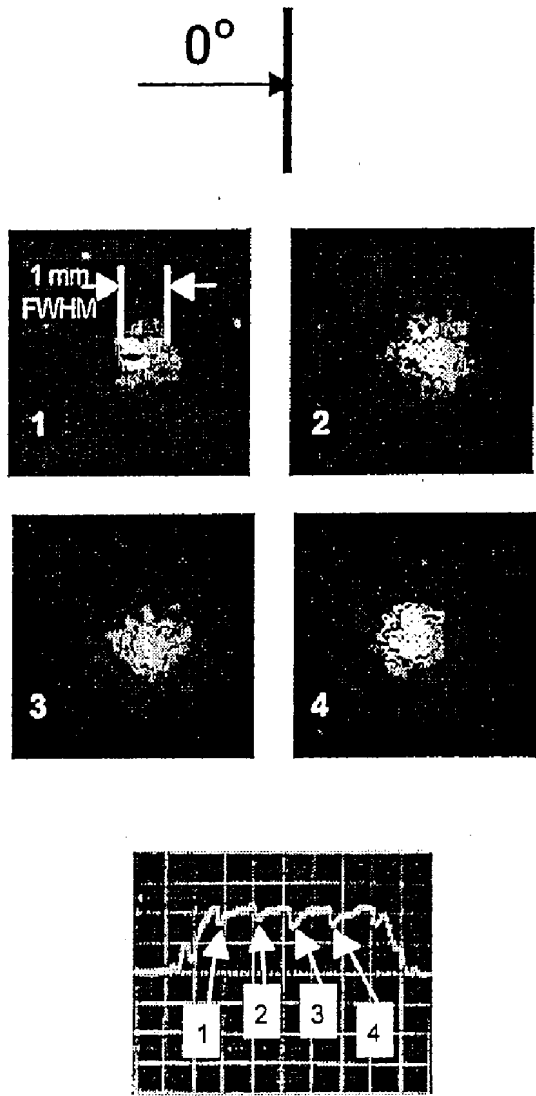

Figure 1: Representative example of $x$-ray pinhole camera images for $(f$ beam incidence. Fiducials correspond to gate time of each photo relative to the beam current pulse on target.

By contrast with this data, we focused a high power laser at the electron beam target interaction point to create a plasma from adsorbates and ensure a source of ions was present (figure $3 \mathrm{a}$ ). Under such conditions, we observed a dynamic spot accompanied by a very prompt positive signature in the upstream Faraday cups (i.e., indicating ions) within $30 \mathrm{~ns}$ following the end of the beam puise (figure 4). We performed these same sets of measurements with a plasma source in the vicinity of the beam and observed similar results.

As a means to limit the effects of the target plume and fast backstreaming ions, we implemented a dielectric barrier in front of the converter target. Figure 5 shows the free expansion of the target plume. Placing a thin dielectric barrier in front of the target suppresses this expansion and limits the extent that the beam can interact with this plume.

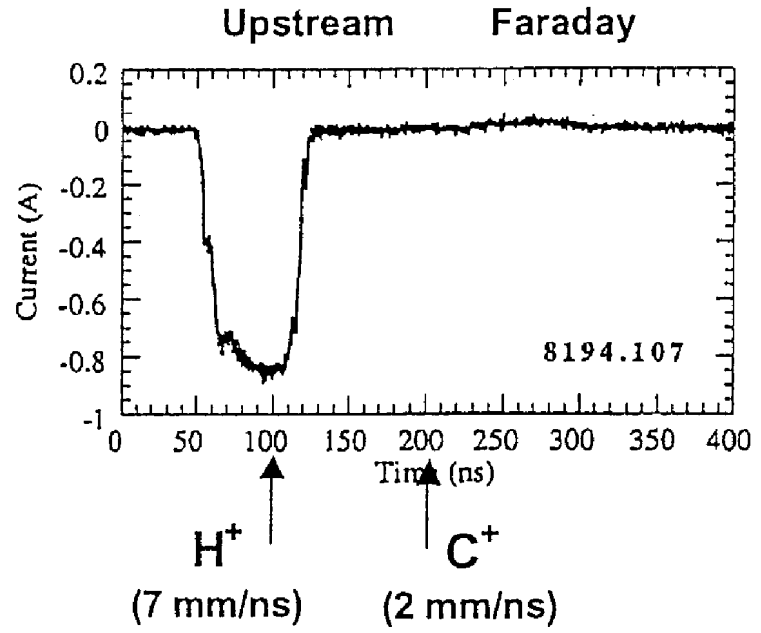

Figure 2: Faraday cup signature in the vicinity of the target. Large negative signa! is from the beam electrons. Arrows at $100 \mathrm{~ns}$ and 210 ns represent location of expected backstreaming ion signature.
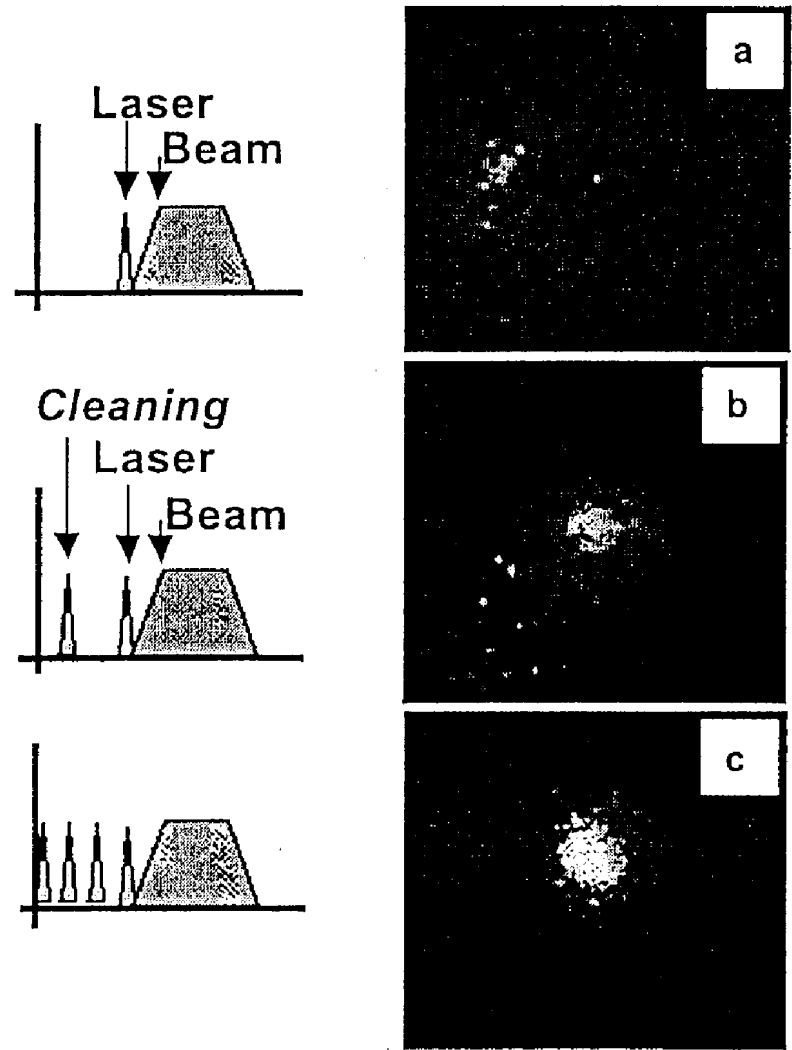

Figure 3: Spot size variation at the end of the ebeam pulse. a) Disrupted spot resulting from a laser induced piasma at the target. Backstreaming ions were observed during this shot. Result of b) single pulse laser cleaning of the surface and c) multipulse laser cleaning of the surface. 


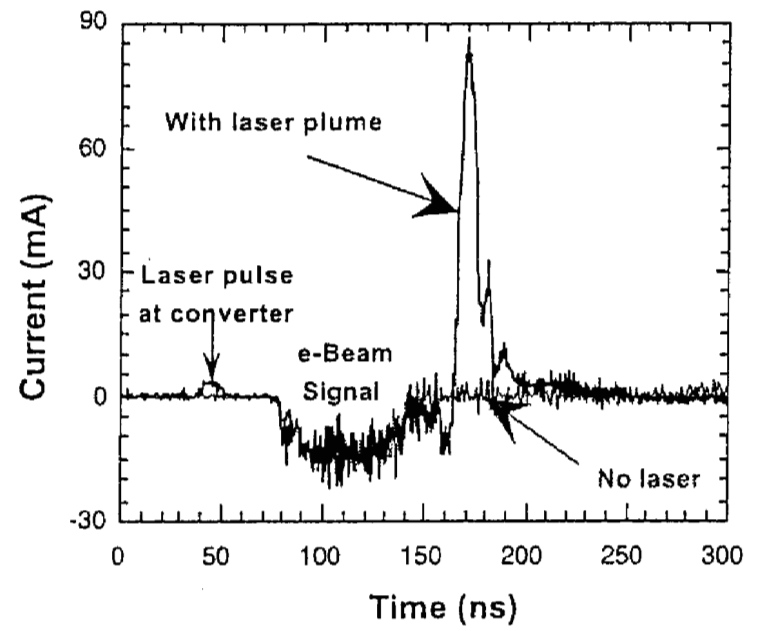

Figure 4: Fast ion signature with and without a laser generated plasma.

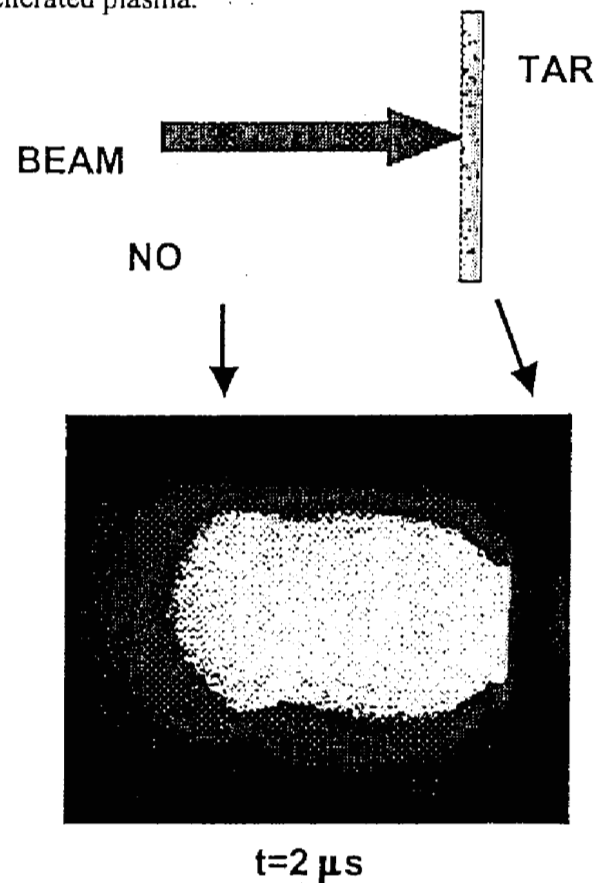

Figure 5: Image of the expanding plume from the converter target

With this dielectric barrier in place, we induced a plasma with the laser at the e-beam target interaction point. Under these conditions, we observe an almost constant spot diameter. This result is compared in Figure 7 to our previous result without laser cleaning (Figure $3 \mathrm{a}$ ).

\section{SUMMARY}

We have developed and implemented methods for suppressing the backstreaming ion effect to ensure a constant xray spot diameter for multipulse radiography targets. Initial tests were performed with a laser-induced plasma. We demonstrated that we were also able to suppress the backstreaming ion effect by laser cleaning the surface or with a mechanical barrier.

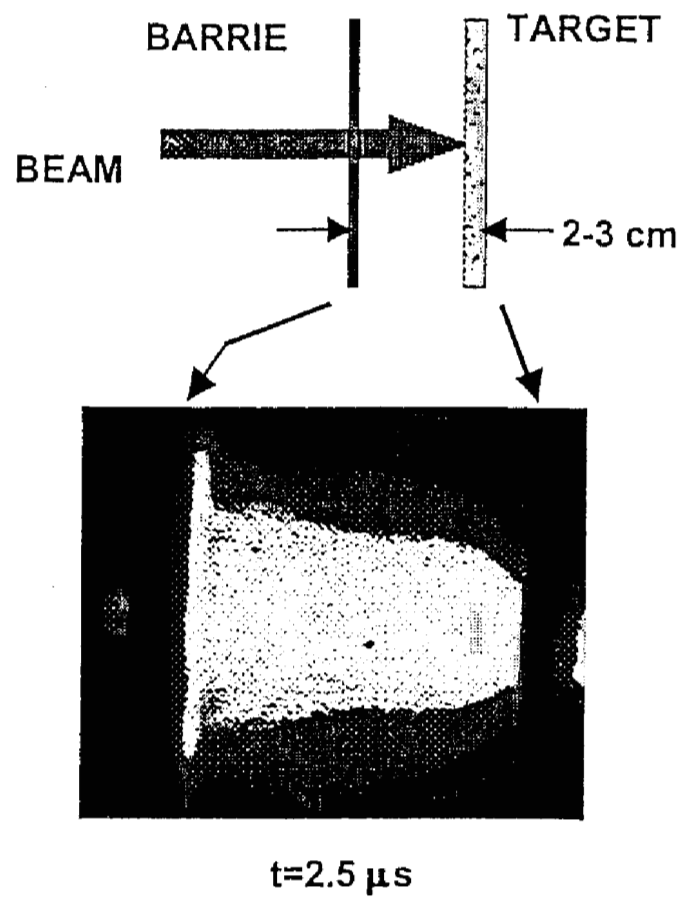

Figure 6: Suppression of the target plume expansion with a dielectric barrier.

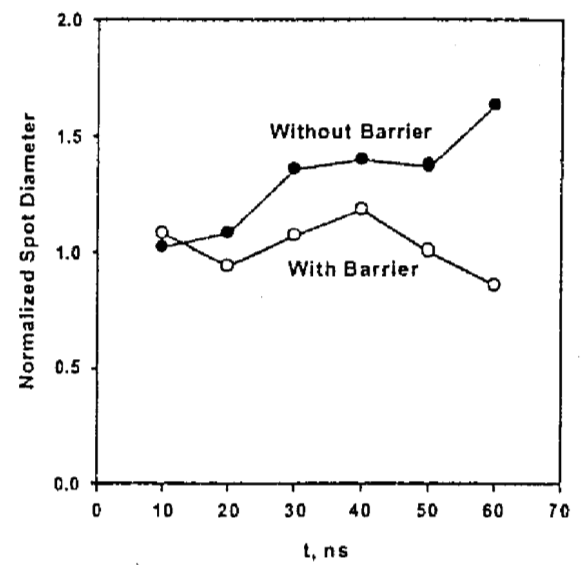

Figure 7: Laser induced plasma in the vicinity of the beamtarget interaction point. X-ray spot size comparison with and without a dielectric barrier in place.

\section{REFERENCES}

* Work performed under the auspices of the US DOE by University of California, Lawrence Livermore National Laboratory under contract No. W-7405-ENG-48.

[1] S. E Sampayan, et. al. "Experimental Investigation of Beam Optics Issues at the Bremsstrahlung Converters for Radiographic Applications", in Proc. 1998 Linear Accelerator Conf. 